Eur J Clin Chem Clin Biochem

1995; 33:87-93

() 1995 Walter de Gruyter \& Co.

Berlin · New York

\title{
A Competitive Polymerase Chain Reaction Assay for Reliable Identification of Bordetella Pertussis in Nasopharyngeal Swabs
}

\author{
By Ralf Lichtinghagen and Ralf Glaubitz \\ Institut für Klinische Chemie I der Medizinischen Hochschule Hannover, Hannover, Germany
}

(Received August 12/November 25, 1994)

Summary: In order to optimize the identification of clinically relevant quantities of Bordetella pertussis in nasopharyngeal swabs, an automated assay introducing competitive polymerase chain reaction was established. A 183 base pair DNA fragment from a repetitive region of the Bordetella pertussis genome was amplified in a polymerase chain reaction. An internal control DNA with nine base substitutions was coamplified in the same reaction. The differentiation between the amplified $B$. pertussis DNA and the internal control was based on hybridisation against two different probes using Enzymun Test ${ }^{\circledR}$ DNA Detection (Boehringer Mannheim). Nasopharyngeal swabs from serologically positive patients, clinically diagnosed with whooping cough, serologically negative patients after contact with $B$. pertussis and a negative group were compared. The advantages of competitive PCR are a reduced risk of false-positive and false-negative results and the possibility to differentiate between the different PCR positive groups.

\section{Introduction}

The importance of the polymerase chain reaction for the identification of the Gram-negative bacterium Bordetella pertussis in nasopharyngeal swabs or aspirates used for early diagnosis of whooping cough or epidemiological studies has increased in recent years. Standard methods like culture of $B$. pertussis or ELISA serology are not sensitive enough or not useful for an early and fast identification of the infectious agent $(1-5)$. For the diagnosis of whooping cough, various parts of the $B$. pertussis genome have been used for amplification in PCR. Assays were described by different authors detecting a part of the pertussis toxin gene (4-7), the adenylate cyclase gene (8) or a repetitive region of the $B$. pertussis genome $(2-4,9-11)$. All regions are shown to be suitable for identification of $B$. pertussis with different cross reactivities in detecting other Bordetellae like B. parapertussis, B. bronchiseptica or B. avium. Our assay involves the amplification of the described repetitive element of the $B$. pertussis genome, because detection of this region results in an increased sensitivity $(2,4)$.
Frequently described problems in the routine use of the polymerase chain reaction include false-positive results due to contaminations, especially by carry over of DNA from other samples or positive controls. Secondly, falsenegative results are obtained due to any disturbances in the entire assay, which involves all parts from DNA isolation to detection of the amplified DNA (11), such as inhibitory effects during PCR amplification. Another problem is the clinical relevance of any positive result in an assay with such a high sensitivity like a nested polymerase chain reaction. In order to investigate the questions we established a competitive polymerase chain reaction $(12,13)$ using a modified part of the repetitive element of $B$. pertussis as internal control. We evaluated our assay by analyzing nasopharyngeal swabs from serologically confirmed children with whooping cough and serologically negative children with proven contact with $B$. pertussis.

\section{Materials and Methods}

Samples

Samples were collected from patients from a pacdiatric practice and from the children's hospital of the Hannover Medical School 
between March 1992 and June 1994. Nasopharyngeal swabs were collected with fine tip dacron swab sets (Transwab MD 173). The samples were placed in $100 \mu$ physiological saline solution in a sterile reaction tube (Eppendorf, $0.5 \mathrm{ml}$ ), resuspended and stored at $-20^{\circ} \mathrm{C}$ until needed.

\section{DNA isolation}

An easy one tube DNA isolation method was performed as previously described by Lichtinghagen et al. (11). A second method for DNA isolation involved proteinase-K treatment and subsequent adsorption of the DNA to a DNA-binding matrix. For this purpose we used QIAamp Blood Kit (Qiagen) according to the manufacturer's instructions.

A third method was to incubate samples for $10 \mathrm{~min}$ at $99^{\circ} \mathrm{C}$, extract the solution with an equal volume of phenol/chloroform $(1+1)$ mixture and precipitate with a threefold volume ethanol. The sedimented DNA was washed with $500 \mu \mathrm{l}$ ethanol $(75 \mathrm{~g} / \mathrm{l})$, dried and dissolved in $100 \mu \mathrm{l} \mathrm{H}_{2} \mathrm{O}$.

\section{Implementation of the polymerase chain reaction}

PCR was performed as described by Saiki et al. with some modifications (14). For a more specific annealing reaction, tetramethylammonium chloride was used in the reaction mix (15). And we also preferred a hot start PCR in order to obtain a higher yield.

Samples $(30 \mu \mathrm{l})$ treated as described above were placed in a 0.5 $\mathrm{ml}$ Eppendorf tube, overlaid with $50 \mu \mathrm{l}$ of paraffin and incubated at $95^{\circ} \mathrm{C}$ for 10 minutes (hot start PCR). PCR-mix $(20 \mu \mathrm{l})$ and 2 units of $T a q$ polymerase ${ }^{1}$ ) were then added at $80^{\circ} \mathrm{C}$ (PCR-mix: see below). The PCR was carried out with the primer pair Perl/Per3rev in a thermocycler (Landgraf) for 35 cycles. The cycles consisted of a denaturation step at $94^{\circ} \mathrm{C}$ for 60 seconds, annealing at $59^{\circ} \mathrm{C}$ for 60 seconds and elongation at $72^{\circ} \mathrm{C}$ for 60 seconds.

The oligonucleotide sequences were:

PERl: 5'-GAT TCA ATA GGT TGT ATG CAT GGT T-3', PER3-rev: $\quad$ 5'-GCT TCA GGC ACA CAA ACT TGA TGG-3',

PCR-mix (50 $\mu$ l total volume): $0.2 \mathrm{mmol} / \mathrm{l}$ dNTPs (Fa. Pharmacia, Boehringer Mannheim), $1 \mu \mathrm{mol} / 1$ each of the oligonucleotides (Perl, Per3rev) HPLC grade (Biometra), $5 \mu$ l PCR buffer (Boehringer Mannheim), $0.05 \mathrm{mmol} / \mathrm{l}$ tetramethylammonium chloride, $2 \mathrm{U}$ Taq polymerase (Cetus, Boehringer Mannheim) ad $20 \mathrm{\mu l} \mathrm{H}_{2} \mathrm{O}$.

For an immunochemical detection, the DNA was labelled with digoxigenin-11-2'-desoxy-uridine-5'-triphosphate, which was added to the desoxynucleoside-triphosphate mixture in a ratio $8: 1$ (dTTP/Dig-11-dUTP). In case of a competitive polymerase chain reaction normally $1 \mathrm{pg}$ internal control DNA was added to the PCR-mix.

\section{Avoiding contamination in the PCR}

In order to avoid false positive results from contaminated PCR samples, only sterile pipette tips with filters (Multy Technology Inc.) were used. The risk of contaminations was further reduced by using apportioned stock mixes to diminish the number of pipet-

\footnotetext{
1) Enzymes:

Taqpolymerase:

EcoRI:

HindIII:

BamHI:

T4 DNA ligase:

DNA polymerase EC 2.7.7.7 from Thermus aquaticus

restriction endonuclease from $E$. coli

restriction endonuclease from Haemophilus influenzae Rd

restriction endonuclease from Bacillus amyloliquefaciens $\mathrm{H}$

DNA ligase from T4-infected $E$. coli
}

ting steps. The competitive polymerase chain reaction made it possible to avoid a separate positive control, which would have been an additional source of contaminations. Working areas for sample preparation, PCR and detection of DNA were strictly separated.

\section{Immunochemical detection of DNA, fragments}

\section{Enzymun Test ${ }^{\circledR}$ DNA detection with an ES 300 analyser}

PCR-specifically amplified and digoxigenin labelled sample were added to $360 \mu \mathrm{l}$ denaturing reagent $(50 \mathrm{mmol} / \mathrm{l} \mathrm{NaOH})$ and pipetted into the ES 300 analyser. The reaction program was started according to the Enzymun Test ${ }^{\circledR}$ DNA Detection instructions (Boehringer Mannheim). The following reagents were also necessary: Biotinylated capture probes were added to different hybridisation solutions (phosphate buffer, $\mathrm{pH} 6.5$ ) to a final concentration of $90 \mu \mathrm{g} / \mathrm{l}$.

Capture probe (B. pertussis assay):

\section{$5^{\prime}$ Biotin-CTG GAC CAT TTC GAG TCG AC 3'}

Capture probe (internal control):

$$
\text { 5' Biotin-CTG CAC GTA GGA TCC TCG AC 3' }
$$

$B$. pertussis specific DNA and the internal control DNA were detected by binding of the biotin labelled nucleic acids to the streptavidin solid phase (Enzymun Test ${ }^{\circledR}$ Streptavidin Tubes, Boehringer Mannheim) in two different reactions. A peroxidase conjugated anti-digoxigenin antibody was added to label the digoxigenin. The complex was then visualized by addition of the chromogen diammonium 2,2'-azino-bis(3-ethylbenzothiazoline-6-sulphonate) (ABTS) giving rise to a green colour, the intensity of which was measured at $422 \mathrm{~nm}$. Positive samples were determined by a cutoff value (cut-off $=2 \times E_{\text {neg }}$ ). Samples which had absorbances between $-25 \%$ and $+50 \%$ of the cut-off value were seen as borderline values and were repeated.

\section{Site directed mutagenesis using polymerase chain} reaction (16)

The whole target DNA region was amplified in two different polymerase chain reactions under standard conditions (14) with the primer pairs R1/R3 and R2/R4. The oligonucleotides R1 and R2 were the flanking primers of the target region with additional recognition sites for $\left.E c o \mathrm{RI}^{1}\right)$ (R1) and $H$ indIII') (R2). The oligonucleotide R3 corresponded to an internal part of this DNA region adjacent to the DNA sequence of oligonucleotide R4. Restriction endonuclease $B a m \mathrm{HI}^{1}$ ) recognition sites at the 5 '-end of the primers R3 and R4 for joining these fragments sites and three additional base substitutions in the sequence of oligonucleotide R4 were introduced.

The sequences were:

R1: TAA GAA TTC GAT TCA ATA GGT TGT ATG CAT GGT R2: TAA AAG CTT CTC CAC GAT AGC CAG CGC CT R3: TAA GGA TCC TCG ACG TAG GAA GGT CAA TCG R4: TAA GGA TCC TAC GTC CAG CAA TTG ATC GCC

The amplified products were gel purified using Sephaglas-Kit (Pharmacia) and cleaved with EcoRI and BamHI (R1/R3) and with HindlII and Bam HI (R2/R4) to obtain DNA ready for ligation. The enzymes were inactivated by phenol/chloroform extraction and ethanol precipitation. DNA fragments were subsequently dissolved in $10 \mu \mathrm{l}$ Tris/EDTA buffer $(10 \mathrm{mmol} / 1$ Tris- $\mathrm{HCl}, \mathrm{pH} 7.9,1 \mathrm{mmol} / \mathrm{h}$ EDTA) and ligated with EcoRI/HindIII ${ }^{1}$ ) digested vector pUCBM20 (Boehringer Mannheim) using T4-DNA-ligase ${ }^{1}$ ) (Boehringer Mannheim). Competent bacterial strain $E$. coli $\mathrm{C} 600$ was transformed with the recombinant plasmid DNA (17).

\section{Plasmid preparation}

LB medium $(500 \mathrm{ml})$ containing $100 \mathrm{mg} / \mathrm{l}$ ampicillin was inoculated with $5 \mathrm{ml}$ of a late $\log$ culture of a positive bacterial clone. 
The culture was incubated under vigorous shaking $\left(180 \mathrm{~min}^{-1}\right)$ at $37^{\circ} \mathrm{C}$ for 6 hours (17). Plasmid preparation was performed according to instructions of Qiagen Plasmid Maxi Kit (Qiagen). The DNA was further extracted with phenol/chloroform and ethanol precipitated after RNase treatment of the plasmid DNA. The preparation was checked on an agarose gel. Agarose gel electrophoresis was performed on $20 \mathrm{~g} / 1$ agarose gels in Tris-borate buffer containing $89 \mathrm{mmol} / \mathrm{l}$ Tris-borate, $2 \mathrm{mmol} / \mathrm{l}$ EDTA, $400 \mu \mathrm{g} / 1$ ethidium bromide, pH 8.0 (17). Electrophoresis was carried out for 45 minutes with $10 \mathrm{~V} / \mathrm{cm}$ in Tris-borate buffer. The DNA bands were detected with an UV transilluminator at $312 \mathrm{~nm}$ (17). The concentration of the DNA was determined by measuring the absorbance at $260 \mathrm{~nm}$. An absorbance of 1.0 corresponds to approximately $50 \mathrm{mg} / \mathrm{l}$ double-stranded DNA (17).

\section{Results}

Cloning the internal control DNA in E. coli

$B$. pertussis DNA isolated from a positive nasopharyngeal swab was amplified in two separate polymerase chain reactions using the primer pairs R1/R3 and R2/R4 (see fig. 1). All primers contained additional recognition sites for restriction endonucleases (see Material and Methods). The joining of the two resulting DNA fragments via the BamHI restriction site of R2 and R4 gen- erated six substitutions in the original sequence. More bases were exchanged by introducing three mismatches next to the cloning site of oligonucleotide R4. After ligation with pUC BM20 and amplification in $E$. coli the recombinant plasmid was purified (see Material and Methods) and used as internal control DNA which was added to the PCR-mix.

\section{Checking the assay conditions with internal control DNA}

First the internal control DNA was tested for cross reactivity after hybridisation with the pertussis capture probe under the described assay conditions (see Material and Methods). For this purpose dilutions of the internal control DNA were prepared from $10^{-8} \mathrm{~g}$ to $10^{-13} \mathrm{~g}$ per assay and amplified in polymerase chain reactions with the primer pair Per1/Per3 rev. Internal control and pertussis capture probe were hybridised with the amplified products in two different reactions. Table 1 shows absorbances at $422 \mathrm{~nm}$ for these two detection steps from dilutions of the internal control DNA. Under standard assay conditions there was no cross reactivity between

a

CTAGCTGTGA AGATTCAATA GGTTGTATGC ATGGTTCATC CGAACCGGAT TTGAGAAACT GGAAATCGCC AACCCCCCAG

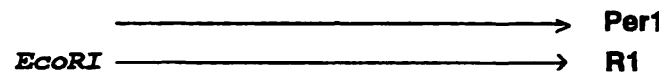

TTCACTCAAG GAGCCCGGCC GGATGAACAC CCATAAGCAT GCCCGATTGA CCTTCCTACG TCGACTCGAA ATGGTCCAGC

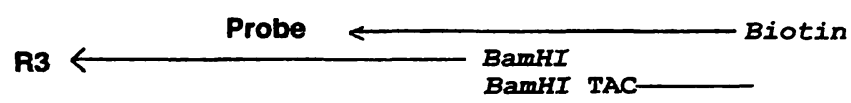

AATTGATCGC CCATCAAGTT TGTGTGCCTG AagcGGCCCG...

-. gGcCAaggce ctgGctatcg tgGagctccg

Per3-rev

$\rightarrow$ R4

R2 HindIII

b
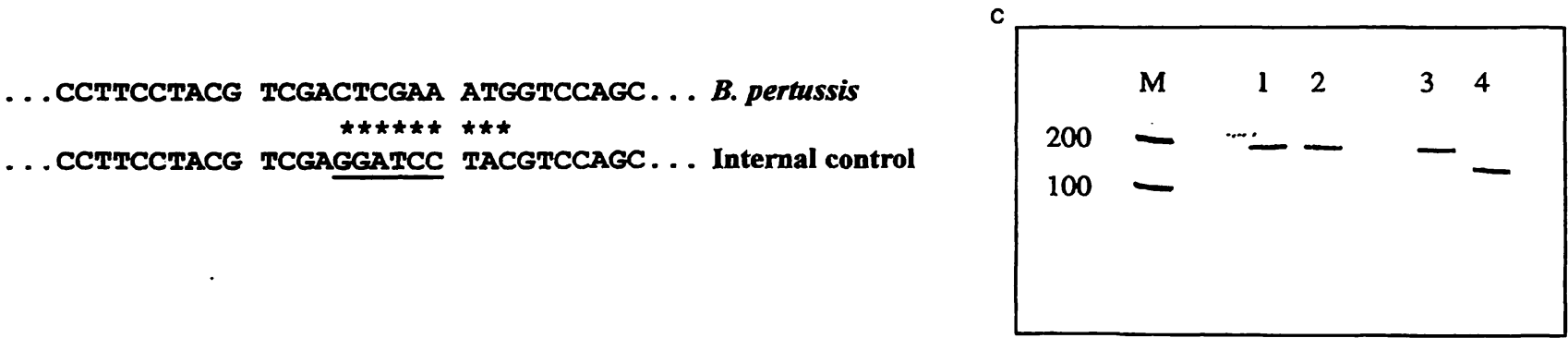

Fig. 1 Construction of the internal control DNA

(a) The PCR amplified section from a repetitive element of $B$. pertussis for detection of the infectious agent in nasopharyngeal aspirates or swabs is shown $(2,11)$. Oligonucleotide sequences used for amplification (see Materials and Methods) are labeled with arrows, additional restriction sites are shown in italics. The resulting DNA fragments have sizes of 183 base pairs (Perl/ Per3rev), 380 base pairs (R1/R2), 145 base pairs (R1/R3) and 241 base pairs (R2/R4). (b) The resulting nine sequence alterations in the internal control DNA after ligating the RI/R3 and R2/R4 DNA fragments with pUCBM20 are marked with asterisks in the sequence of the capture probe binding region.

(c) Electrophoretic separation of $B$. pertussis DNA (lane 1) and internal control DNA (lane 2) after PCR with primer pair Perl/ Per3rev results in 183 base pairs DNA fragments. After digestion with restriction endonuclease $B a m H I$ (lane $3: B$. pertussis DNA. lane 4: internal control DNA) bands of 138 and 45 base pairs were only detected in lane 4. 
Tab. 1 Test for cross reactivity of the internal control DNA with the pertussis capture probe.

The cloned internal control DNA was diluted in several steps $\left(10^{-8}\right.$ - $10^{-13}$ g per assay) and amplified in a PCR using the primer pair Perl/Per3rev (see Materials and Methods). Two capture probes (pertussis, internal control) were used for hybridisation: Absorbances at $422 \mathrm{~nm}$ after detection of the PCR products with the ES300 analyser (Enzymun Test ${ }^{\circledR}$ DNA Detection) are shown.

\begin{tabular}{lllllll}
\hline Quantity [g] & $10^{-8}$ & $10^{-9}$ & $10^{-10}$ & $10^{-11}$ & $10^{-12}$ & $10^{-13}$ \\
\hline $\begin{array}{l}\text { Pertussis } \\
\text { capture probe }\end{array}$ & 0.044 & 0.041 & 0.041 & 0.039 & 0.043 & 0.034 \\
$\begin{array}{l}\text { Internal control } \\
\text { capture probe }\end{array}$ & 6.66 & 6.72 & 6.69 & 6.50 & 6.50 & 5.89 \\
\hline
\end{tabular}

internal control DNA and pertussis capture probe. Thus the introduced mismatches in the capture probe binding site are shown to be suitable for a differentiation of $B$. pertussis and internal control in the assay.

The use of competitive PCR may result in a decreased amplification rate of the required DNA fragment. Therefore it was necessary to determine a minimum quantity of internal control DNA which could be coamplified in polymerase chain reaction. Table 2 shows the results of these investigations. Internal control DNA was diluted from $10^{-8} \mathrm{~g}$ to $10^{-15} \mathrm{~g}$ per assay. From each dilution four amplifications were performed and the products were detected with internal control capture probe using Enzymun Test ${ }^{\circledR}$ DNA Detection. Internal control DNA ( $1 \mathrm{pg}$ per $50 \mu \mathrm{l}$ total volume in the reaction mixture) was the lowest concentration which led to constant absorbances at $422 \mathrm{~nm}$. This fact is indicated by the increasing coefficients of variation at lower quantities of internal control DNA. Furthermore we tested the competitive PCR with dilutions from $10^{-8} \mathrm{~g}$ to $10^{-14} \mathrm{~g}$ per assay of the repetitive DNA fragment of $B$. pertussis cloned into pBluescript SK+ (11) and a constant amount of $1 \mathrm{pg}$ internal control DNA per reaction (see fig. 2). As expected we found a suppression of internal control DNA amplification at higher $B$. pertussis DNA concentrations and vice versa. In ten different runs we investigated mean values for negative controls. We found for internal control capture probe $\mathrm{A}_{422 \mathrm{~nm}}=5.83, \mathrm{SD}=0.6$ $(\mathrm{n}=20)$ and for pertussis capture probe $\mathrm{A}_{422 \mathrm{~nm}}$ $=0.046, \mathrm{SD}=0.02(n=20)$. The cut-off value for negative samples was set at $\mathrm{A}_{422 \mathrm{~nm}}$ (pertussis capture probe) $<0.1$ which is due to Enzymun Test ${ }^{\circledR}$ DNA Detection specifications (negative sample $<2 \times \mathrm{A}_{422} \mathrm{~nm}$ ).

\section{Competitive polymerase chain reaction with patient samples}

For reliable identification of Bordetella pertussis in nasopharyngeal swabs it was necessary to check the quality of the described assay conditions. Therefore we tested different pools of stored patient samples. The first group includes patients without any signs of infection which tested negative in a polymerase chain reaction (11). The absorbances after detection of the amplified DNA using pertussis capture probe were in the same range compared to the negative controls $\left(A_{422 \mathrm{~nm}}\right.$ $=0.03, \mathrm{SD}=0.002(\mathrm{n}=10))$. Measuring negative patient samples it was possible to study inhibitory effects of the DNA preparation techniques used in the assay. We tested a commercial DNA preparation kit and two usual methods for DNA preparation (see materials ând methods). The dependence of the quality of DNA preparation methods on internal control DNA amplification is shown in table 3. Coamplification of $1 \mathrm{pg}$ internal control DNA in a competitive PCR with reproducible high absorbances in the detection step was only possible using phenol/chloroform purified DNA from nasopharyngeal swabs. In cases in which other DNA preparation methods were used it became necessary to increase the amount of internal control DNA.

Finally we compared serologically confirmed patients with whooping cough and PCR-positive, serologically negative patients with proven contact to $B$. pertussis. With these test results we wanted to show a possible detection of different amounts of the infectious agents in nasopharyngeal swabs between the point of infection and the paroxysmal stage. Results of these comparisons are shown in figure 3. Positive tests were confirmed in both groups using a competitive PCR assay. In addition, a ratio of absorbances at $422 \mathrm{~nm}$ of the $B$. pertussis
Tab. 2 Determining the minimum quantity of internal control DNA in the assay.

Internal control DNA was diluted in several steps $\left(10^{-8}-10^{-15} \mathrm{~g}\right.$ per assay) and PCR amplified using the primer pair Perl/Per3rev (see Materials and Methods). From each dilution four amplifications were performed. Hybridisation occured only with the internal control capture probe. Mean values, standard deviations and coefficients of variation are shown for the measured absorbances at $422 \mathrm{~nm}$.

\begin{tabular}{llllllllr}
\hline Quantity [g] & $10^{-8}$ & $10^{-9}$ & $10^{-10}$ & $10^{-11}$ & $10^{-12}$ & $10^{-13}$ & $10^{-14}$ & $10^{-15}$ \\
\hline Mean value & 6.70 & 6.53 & 6.67 & 6.53 & 6.34 & 1.65 & 0.07 & 0.82 \\
Standard deviation & 0.04 & 0.07 & 0.13 & 0.11 & 0.2 & 1.87 & 0.05 & 1.57 \\
Coefficient of variation [\%] & 1 & 1 & 2 & 2 & 3 & $113:$ & 71 & 191 \\
\hline
\end{tabular}




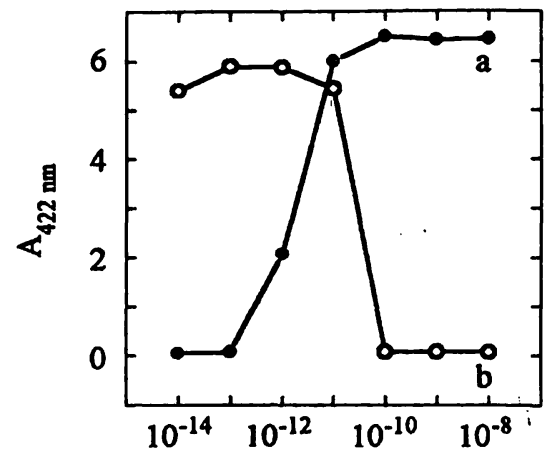

Positive control DNA [g]

Fig. 2 Competitive polymerase chain reaction of positive control DNA

The $B$. pertussis DNA fragment (183 base pairs; Perl/Per3rev) cloned in pBluescript $\mathrm{KS}+(11)$ was diluted from $10^{-8} \mathrm{~g}$ to $10^{-15} \mathrm{~g}$ per assay and coamplified with $10^{-12} \mathrm{~g}$ internal control DNA. The primers Perl and Per3rev were used in the PCR. Resulting DNA fragments were detected after hybridisation with pertussis (a) and internal control capture probe (b) using Enzymun Test ${ }^{\circledR}$ DNA Detection (see Materials and Methods). Absorbances at 422 nm were plotted against concentrations of positive control plasmid DNA.

DNA and the internal control DNA led to a better separation of different collectives. In case of the serologically negative group we found maximum values only around 1.5 (values for negative samples were about 0.01 ). In the serologically positive group values between 10 and 100 could be obtained. Such a differentiation was not possible in a comparison only of the absorbances of the amplified $B$. pertussis DNA. To determine the influence of the concentration of internal control DNA on the sensitivity of the assay, we investigated pooled samples from serologically positive and negative patients with high absorbances in the detection assay $(>6.0)$, and samples with low absorbances $(<0.3)$.

From these pools four competitive PCR assays were performed with increasing concentrations $\left(10^{-12}\right.$ $-10^{-9} \mathrm{~g}$ per assay) of the internal control DNA. In

Tab. 3 Effect of DNA preparation technique on internal control DNA amplification.

Samples from patients without any signs of wooping cough were amplified in a competitive PCR with $1 \mathrm{pg}$ internal control DNA after different routes of DNA isolation. Mean values for absorbances at $422 \mathrm{~nm}$ after hybridisation with internal control capture probe, standard deviations and coefficients of variation are listed.

\begin{tabular}{llllr}
\hline DNA preparation method & $\mathrm{n}$ & $\overline{\mathbf{x}}_{\text {internal control }}$ & SD & $\begin{array}{r}\mathrm{CV} \\
(\%)\end{array}$ \\
\hline $\begin{array}{l}\text { Proteinase-K treatment } \\
\text { and boiling of the sample }\end{array}$ & 35 & 0.054 & 0.003 & 6 \\
QIAamp Blood Kit & 25 & 0.71 & 0.91 & 128 \\
Phenol/chloroform & 10 & 4.47 & 0.37 & 8 \\
\hline
\end{tabular}

case of the positive group a competition with about $10^{-9} \mathrm{~g}$ internal control DNA and in case of the negative group with about $10^{-11}$ to $10^{-12} \mathrm{~g}$ leads to a ratio of 1 which indicates an equimolar amount of $B$. pertussis and internal control DNA fragment. This shows that using an amount of $10^{-12} \mathrm{~g}$ of internal control plasmid DNA does not lead to a decreased diagnostic sensitivity of the assay.

\section{Discussion}

Usually the diagnosis of whooping cough can be done definitively with the help of polymerase chain reaction. But in some cases a bad correlation between laboratory results and the clinical picture leads to a decrease of diagnostic specificity and sensitivity. Diagnostic specificity can be optimized by amplification of a proven germ specific DNA area (4-11), and by following hygienic precautions, like isolating the work areas and using filter tips for pipetting (11). In contrast to serology and culture, high sensitivity of PCR allows the detection of $B$. pertussis in early stages of disease

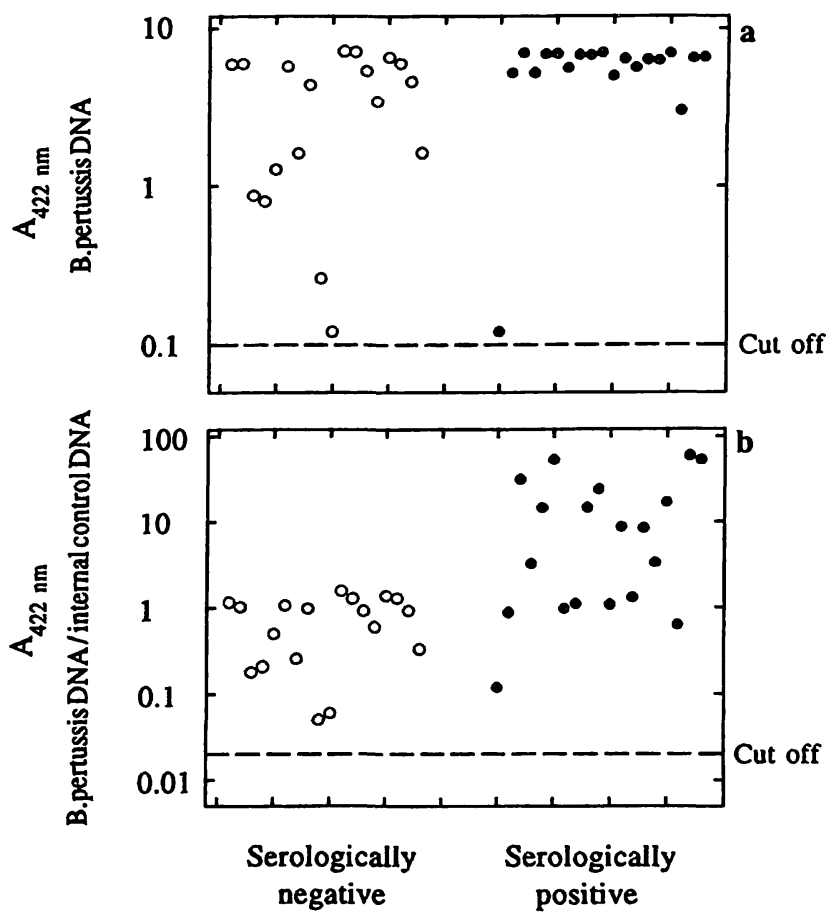

Fig. 3 Competitive polymerase chain reaction with purified DNA from nasopharyngeal swabs

Bordetella pertussis DNA was isolated from nasopharyngeal swabs using phenol/chloroform extraction (see Materials and Methods). Two groups of patients were tested in this comparison. Serologically negative children without typical clinical presentations but proven contact to $B$. pertussis and serologically positive children with typical signs of ivhooping cough. Resulting DNA fragments were detected after hybridisation with pertussis and internal control capture probe using Enzymun Test ${ }^{\circledR}$ DNA Detection. Absorbances at $422 \mathrm{~nm}$ for pertussis capture probe are shown in (a). The listed values in (b) are the ratios $A_{422 \mathrm{~nm}}\left(B\right.$. pertussis) $/ A_{422 \mathrm{~nm}}$ (internal control DNA). 
and in case of infections of vaccinized patients $(3,11$, $18,19)$.

Competitive PCR is a useful tool in the identification of a diminished diagnostic sensitivity. Loss of sensitivity in PCR assays is mostly due to inhibitory effects (20); e.g. we found an influence on the amplification of the target DNA due to insufficient inactivated proteinase $\mathrm{K}$ (see tab. 3), sometimes to haemoglobin and incomplete removal of phenol. During a competitive PCR an internal control DNA is coamplified. A diminished amplification of the internal control DNA discloses such disturbances in case of a negative detection of the target DNA. From our point of view one can omit a separate positive control like a cloned DNA fragment for quality control because it does not give any evidence of inhibitors in the individual sample and it presents a potential source of contamination.

Depending on the concentration of the internal control DNA, its coamplification leads to a reduction of the amplification rate of the target DNA (see fig. 1). The sensitivity of the assay therefore has to be calibrated according to these demands (see fig. 4), so that the clinically
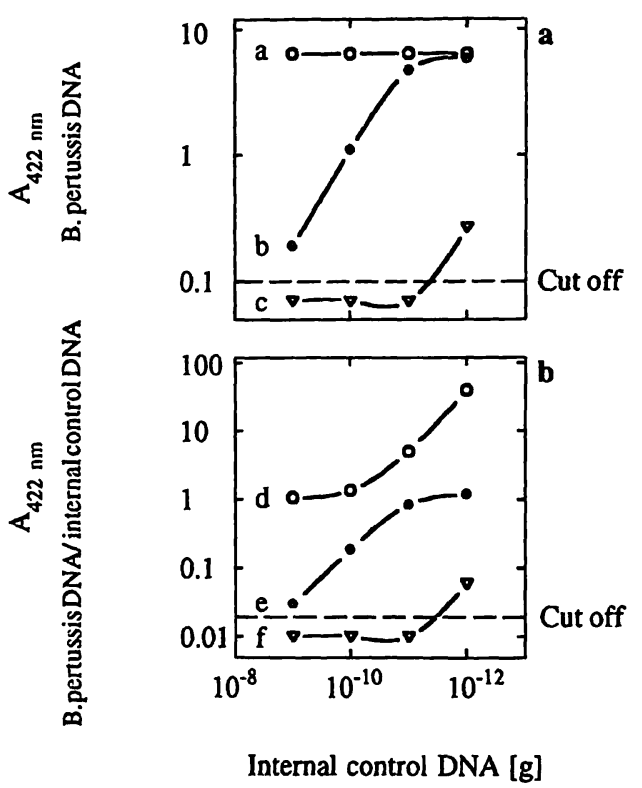

Fig. 4 Competition of different concentrations of B. pertussis DNA isolated from nasopharyngeal swabs

Pooled samples from serologically positive children with whooping cough $(a, d)$, from serologically negative children with contact to $B$. pertussis and high absorbances after pertussis capture probe hybridisation $(b, e)$ and samples with low absorbances after hybridisation with pertussis capture probe $(c, f)$ were tested in competitive $\mathrm{PCR}$ assays with increasing amounts of internal control DNA $\left(10^{-12}-10^{-9} \mathrm{~g} /\right.$ assay $)$.

Absorbances at $422 \mathrm{~nm}$ after hybridisation with pertussis capture probe were plotted against internal control DNA quantities per assay (a).

Ratios $\mathrm{A}_{422 \text { mn }}$ (B. pertussis DNA)/A $\mathrm{A}_{422 \mathrm{~nm}}$ (internal control DNA) were plotted against internal control DNA quantities per assay (b). relevant germ DNA concentration does not lie beneath the cut off value.

Today a quantitative interpretation of PCR results is partly possible in the diagnostics of virus diseases from homogeneous matrices like blood (13). For detection of $B$. pertussis nasopharyngeal swabs are suitable, but in this case they can be used only with limitations. $B$. pertussis is an obligate pathogen, therefore each positive result, e.g. after cultivation of the infectious agent, is of clinical relevance. Quantitative results, however, lead to a different assessment of the clinical situation. Using the competitive PCR we could show that a significant differentiation is possible between patients with typical clinical symptoms and patients in prodromal stage. For example it can be of interest to estimate the infectiousness during incubation stage. This is possible with the help of the target DNA/control DNA ratio.

A known disadvantage of a PCR assay is the detection of dead bacterial cells. Regarding the estimation of infectiousness the microbiological culture shows a better diagnostic specificity. Here positive results correlate well with the clinical condition. Therefore the PCR has priority in early diagnostics. With existing older infễctions a possibly still existing infectiousness can not be estimated because the bacteria die during the catarrhal stage. We obtained very weak positive results in some PCR positive patients who had proven contact with $B$. pertusis infected persons (see fig. 4). A semiquantitative estimation with the help of the competitive PCR points to a number of bacterial cells that is clearly below normally measured values (see fig. 4). After a few days a control test should give further information about the infectiousness under consideration of the target DNA control DNA ratio.

We find the competitive PCR to be a fast and dependable procedure for the diagnosis of whooping cough. Analytical sensitivity of single assays could be better controlled. The specificity of a result can be interpreted under consideration of the clinical condition and including the relation of target DNA to internal control DNA amplification. The clinical impact of the competitive PCR with weak positive results must be tested with a much bigger number of samples in correlation with the clinical findings.

\section{Acknowledgements}

The authors highly appreciate the skilful technical assistance of Bernadette Luens and Frank Dsiosa. We are grateful to Dr. $M$. Scherf, Dr. U. Fahlbusch, Dr. D. Petersen and Dr. R. Zinck for helpful discussion. We thank Boehringer Mannheim for support, which made part of this work possible. 


\section{References}

1. Onorato IM, Wassilak SGF. Laboratory diagnosis of pertussis: the state of the art. Pediatr. Infect. Dis. J. 1987; $6: 145-51$.

2. Glare MG, Paton RP, Lawrence JL, Nisnet $\mathbb{I N}$. Analysis of a repetitive DNA sequence from Bordetella pertussis and its application to the diagnosis of pertussis using the Polymerase Chain Reaction. J Clin Microbiol 1990; 28:1982-7.

3. He Q, Mertsola J, Soini H, Skurnik M, Ruuskanen O, Viljanen MK. Comparison of polymerase chain reaction with culture and enzyme immunoassay for diagnosis of pertussis. $\mathrm{J}$ Clin Microbiol 1993; 31:642-5.

4. He Q, Mertsola J, Soini H, Viljanen MK. Sensitive and specific polymerase chain reaction for detection of Bordetella pertussis in nasopharyngeal specimens. J Pediatr $1994 ; 124: 421-6$.

5. Grimprel E, Begue P, Anjak I, Betsou F, Guiso N. Comparison of polymerase chain reaction, culture and western immunoblot serology for diagnosis of Bordetella pertussis infection. J Clin Microbiol (United States) 1993; 31:2745-50.

6. Reizenstein E, Johansson B, Mardin L, Abens J, Mollby R, Hallander HO. Diagnostic evaluation of polymerase chain reaction discriminative for Bordetella pertussis, B. parapertussis and B. bronchiseptica. Diagn. Microbiol. Infect. Dis. (United States) $1993 ; 17: 185-91$.

7. Houard S, Hackel C, Herzog A, Bollen A. Specific identification of Bordetella pertussis by the polymerase chain reaction. Res Microbiol. 1989; 140:477-87.

8. Douglas E, Coote JG, Parton R, McPheat W. Identification of Bordetella pertussis in nasopharyngeal swaps by PCR amplification of a region of the adenylate cyclase gene. J. Med. Microbiol. 1993; 38:140-4.

9. McPheat, WL, McNally T. Isolation of a repeated DNA sequence from Bordetella pertussis. J. Gen. Microbiol. 1987; 133:323-30.

10. Olcen P, Backman A, Johansson B, Esbjorner E, Tornqvist E, Bygraves $J$ et al. Amplification of DNA by the polymerase chain reaction for the efficient diagnosis of pertussis. Scand J. Infect. Dis. 1992; 24:339-45.
11. Lichtinghagen $R$, Diedrich-Glaubitz $R$, von Hörsten B. Identification of Bordetella pertussis in nasopharyngeal swabs using the polymerase chain reaction: Evaluation of detection methods. Eur. J. Clin. Chem. Clin. Biochem. 1994; 32:161-7.

12. Perre F. Quantitative or semi-quantitative PCR: reality versus myth. PCR Methods Appl. 1992; 2:1 -9.

13. Clementi M, Menzo S, Bagnarelli P, Manzin A, Valenza A, Varaldo PE. Quantitative PCR and RT-PCR in virology. PCR Methods Appl. 1993; 2:191-6.

14. Saiki RK, Gelfand DH, Stoffel S, Scharf SJ, Higuchi R, Horn GT. Primer-directed enzymatic amplification of DNA with a thermostable DNA polymerase. Science 1988; 239:487-91.

15. Hung T, Mak K, Fong K. A specific enhancer for polymerase chain reaction. Nucl. Acids Res. 1990; 18:4953.

16. McPherson MJ. Directed mutagenesis - a practical approach. Oxford University Press, New York, 1991.

17. Maniatis, T, Fritsch EF, Sambrook J. Molecular cloning: A laboratory manual. Cold Spring Harbor Laboratory, Cold Spring Harbor, N. Y., 1982.

18. Public Health Laboratory Service Epidemiological Research Laboratory and 21 Area Health Authorities. Efficacy of pertussis vaccination in England. Br. Med. J. 1982; 285:257-9.

19. Schlapfer G, Cherry JD, Heininger U, Just M. Use of the polymerase chain reaction to increase the identification of $B$. pertussis infections in vaccinees and family members in a pertussis vaccine efficacy trial. Pediatr. Res. 1994; 35 (4 Pt 20):195A.

20. Wadowsky RM, Laus S, Libert T, States SJ, Ehrlich GD. Inhibition of PCR-based assay for Bordetella pertussis by using calcium alginate fiber and aluminium shaft components of a nasopharyngeal swab. J. Clin. Microbiol. 1994; 32:1054-7.

Dr. Ralf Lichtinghagen

Medizinische Hochschule Hannover

Institut für Klinische Chemie I

Konstanty-Gutschow-Straße 8

D-30625 Hannover

Germany 
$-$ 